\section{Retinopathy of prematurity in practice. II: long- term results following treatment for threshold disease}

L Gnanaraj, R Brennan and DG Cottrell

\begin{abstract}
Objective To determine the long-term outcome of treatment for threshold retinopathy of prematurity (ROP) in one UK unit.

Methods A total of 35 infants diagnosed with threshold ROP were treated by a single ophthalmologist (DGC) between 1987 and 1998. The parents of the 29 surviving patients were contacted; 21 brought their child for special review of acuity, motility, refraction and fundoscopy (Group 1). Of the eight patients who were unable to attend, six patients (Group 2) had sufficient follow-up detail in their records to be included in the study.

Results A total of 40 eyes in the 21 patients in Group 1 had been treated; 10 had received cryotherapy (eight bilateral) and 11 had bilateral laser. Mean follow-up was 5 years (range 2-12 years). A total of 23 treated eyes (in 16 patients) had an acuity of $6 / 12+(57.5 \%$ of treated eyes). Four eyes of three patients had no light perception. Seven eyes in four patients had myopia of more than $3 \mathrm{D}$. Eight patients had a manifest squint: six esotropia, two exotropia. The retinal status of 36 eyes $(90 \%)$ showed a favourable outcome. The four blind eyes had stage 5 disease. In Group 2, four eyes of two patients $(33 \%)$ had $6 / 12+$ acuity recorded; five eyes in three patients had stage 5 disease and no perception of light. In total, a favourable structural outcome was achieved in $81.4 \%$ and favourable functional outcome observed in $74.6 \%$.

Conclusion These results show that the favourable outcomes reported in the CRYOROP trial can be achieved in routine practice and maintained after long follow-up.

Eye (2003) 17, 189-193. doi:10.1038/

sj/eye/6700295
\end{abstract}

Keywords: retinopathy of prematurity; threshold disease; treatment; cryotherapy; laser therapy; long-term outcome

\section{Introduction}

In the past two decades, advances in neonatal intensive care have seen the prognosis for premature infants improve significantly. This is associated with a concomitant increase in retinopathy of prematurity (ROP). ${ }^{1-3}$ If untreated, ROP can result in serious ocular sequelae. The multicentre cryotherapy for retinopathy of prematurity (CRYO-ROP) study $^{4-9}$ for the first time clearly demonstrated a beneficial effect of treatment for threshold stage $3+$ ROP. In recent years, diode laser photocoagulation ${ }^{10-14}$ through a binocular indirect ophthalmoscope has gained popularity.

Some previous studies ${ }^{10-12,15-18}$ have confirmed a reduction in incidence of unfavourable structural outcome with treatment and a few of them have presented their functional results. We present a study involving special review of a consecutive series of children treated for ROP using cryotherapy and/or laser photocoagulation.

\section{Materials and methods}

All premature infants who received treatment for ROP with cryotherapy and/or laser photocoagulation by a single surgeon (DGC) between 1987 and 1998 were identified. ${ }^{19}$ The parents of the 29 surviving patients were contacted to participate in the prospective study. A total of $21(72.4 \%)$ children (Group 1) attended a special clinic to assess visual acuity, motility, cycloplegic refraction and fundoscopy. The records of the eight patients who were
Department of Ophthalmology Royal Victoria Infirmary Newcastle-upon-Tyne UK

Correspondence: DG Cottrell Department of Ophthalmology Royal Victoria Infirmary Queen Victoria Road Newcastle-upon-Tyne NE1 4LP, UK

Tel: +1912825450 Fax: +1912275246 E-mail: d.g.cottrell@ ncl.ac.uk

Received: 30 July 2001 Accepted in revised form: 7 May 2002

Presented in part as a poster at the Royal College of Ophthalmologists Congress, Birmingham, UK, May 2001 and as a poster at the European Strabismological Association 27th Annual Meeting, Florence, Italy, June 2001 
Table 1 Visual assessment methods

\begin{tabular}{ll}
\hline Cardiff cards & 6 \\
Kay pictures & 4 \\
Crowded Log $\operatorname{Mar}_{\text {MAR }}$ & 2 \\
Snellen visual acuity & 9 \\
\hline
\end{tabular}

unable to attend were reviewed to maximise the available data; of these, six (Group 2) contained sufficient data to justify their inclusion in the study.

The stage and location of the ROP had been recorded according to the international classification of ROP. ${ }^{20}$ Threshold ROP was defined as five contiguous clock hours or eight cumulative clock hours of stage 3 ROP in zone I or II in the presence of plus disease. Success or failure of treatment was defined on a structural basis in accordance with the CRYO-ROP study: an unfavourable outcome was defined as (1) posterior retinal fold involving the macula, (2) total retinal detachment or total pupillary occlusion by a fibrovascular membrane or (3) retrolental tissue obscuring the view of the posterior pole. All eyes with other fundus appearances were classified as having a favourable outcome. A favourable visual outcome was defined as a visual acuity of better than $6 / 60$; a visual acuity of $6 / 60$ or worse was classified as unfavourable.

Treatment was administered by a single ophthalmologist (DGC) in a tertiary referral centre under general anaesthesia. From 1987 to 1994, cryotherapy was used exclusively; thereafter, 810 or $532 \mathrm{~nm}$ laser was the primary therapy although two infants (four eyes) having laser subsequently had top-up cryotherapy.

Cryotherapy was applied contiguously to the entire circumference of the avascular retina anterior to the ridge. Laser burns were placed anterior to the ridge in a scatter pattern, less than one burn width apart, throughout the avascular retina.

An experienced orthoptist made all the visual assessments, and the methods employed (Table 1) varied according to the age and mental ability of the child. In three infants, only binocular visual acuity was obtainable using Cardiff cards. Motility was assessed by cover test. Cycloplegic refraction ( $1 \%$ cyclopentolate) was then performed by an experienced optometrist, and the retinal status was assessed by one of two qualified ophthalmologists (LG, RB).

For the purpose of this study, we divided the treated children into two groups: Group 1, who attended the special review clinic and Group 2, who were unable to attend. Each group was subdivided into cryotherapy and laser subgroups for data analysis. Fisher's exact test was used for statistical analysis.
Table 2 Demographic data

\begin{tabular}{lcc}
\hline & Group 1 & Group 2 \\
\hline Infants & 21 & 6 \\
Treated eyes & 40 & 12 \\
Birth weight (g) & & \\
$\quad$ Mean (range) & $864.8(570-2300)$ & $813(580-1210)$ \\
Gestational age (weeks) & & \\
$\quad$ Mean (range) & $25.9(23-30)$ & $26.3(23-29)$ \\
Treatment age (weeks) & & \\
$\quad$ Mean (range) & $10.3(7-14)$ & $10.5(7-14)$ \\
Zone of ROP (eyes) & & \\
$\quad$ Zone I & 2 & Nil \\
$\quad$ Zone II & 38 & 12 \\
Maximum stage of ROP at & & \\
treatment (eyes) & & 12 \\
$\quad$ Stage 3 & 39 & 0 \\
$\quad$ Stage 4 & 1 & \\
Primary treatment modality & & 8 \\
(eyes) & & \\
$\quad$ Cryotherapy & 18 & \\
$\quad$ Laser & 22 & \\
\hline
\end{tabular}

\section{Results}

Between November 1987 and October 1998, 503 preterm infants were screened. ${ }^{19}$ In all, 25 infants with disease at or beyond threshold disease were identified and underwent treatment using cryotherapy or laser photocoagulation. A further 10 infants with similar disease were referred from peripheral units for treatment. Six of the infants subsequently died and in two cases records were inadequate leaving a total of 27 infants (52 eyes) included in this study.

The demographics of the infants are summarised in Table 2. A total of 12 infants (22 eyes) were treated with cryotherapy and 15 infants (30 eyes) were treated with either $810 \mathrm{~nm}$ (20 eyes) or $532 \mathrm{~nm}$ laser photocoagulation (10 eyes). The average number of screening examinations before diagnosis of threshold ROP was 4 with a range 17. The mean chronological age of the infant at diagnosis of threshold ROP was 10.4 weeks. The maximum stage of ROP at treatment was stage 3 in $98.1 \%(51 / 52)$ and was located in zone 2 in $96.2 \%(50 / 52)$ of the eyes. The one eye with stage 4 disease was that of an infant referred from a peripheral unit. Threshold disease was unilateral in two infants and they were treated with cryotherapy.

When data from Groups 1 and 2 were combined, a favourable structural outcome (Table 3) was achieved in $72.7 \%(16 / 22)$ of the cryotherapy group and $90 \%(27 / 30)$ of the laser group. Two eyes in the cryotherapy group had a peripheral, temporal localised tractional retinal detachment with a flat posterior pole, and their corrected visual acuity was $6 / 18$. Six eyes in the cryotherapy and three eyes in the laser group developed a total retinal detachment. 
Table 3 Overall structural outcome

\begin{tabular}{|c|c|c|c|c|c|c|}
\hline & \multicolumn{2}{|c|}{ Group 1} & \multicolumn{2}{|c|}{ Group 2} & \multicolumn{2}{|c|}{ Total } \\
\hline & Cryo & Laser & Cryo & Laser & $\begin{array}{c}\text { Cryo } \\
\text { Eyes }(\%)\end{array}$ & $\begin{array}{c}\text { Laser } \\
\text { Eyes (\%) }\end{array}$ \\
\hline Favourable & 14 & 22 & 2 & 5 & $16(72.7 \%)$ & $27(90 \%)$ \\
\hline Unfavourable & 4 & Nil & 2 & 3 & $6(27.3 \%)$ & $3(10 \%)$ \\
\hline
\end{tabular}

Table 4 Overall visual outcome

\begin{tabular}{|c|c|c|c|c|c|c|}
\hline & \multicolumn{2}{|c|}{ Group 1} & \multicolumn{2}{|c|}{ Group 2} & \multicolumn{2}{|c|}{ Total } \\
\hline & Cryo & Laser & Cryo & Laser & $\begin{array}{c}\text { Cryo } \\
\text { Eyes (\%) }\end{array}$ & $\begin{array}{c}\text { Laser } \\
\text { Eyes (\%) }\end{array}$ \\
\hline $6 / 6-6 / 12$ & 8 & 15 & 2 & 2 & $10(45.5 \%)$ & $17(56.7 \%)$ \\
\hline $6 / 18-6 / 60$ & 3 & 7 & 0 & 3 & $3(13.6 \%)$ & $10(33.3 \%)$ \\
\hline$<6 / 60$ & 3 & 0 & 0 & 0 & $3(13.6 \%)$ & 0 \\
\hline NPL & 4 & 0 & 2 & 3 & $6(27.3 \%)$ & $3(10 \%)$ \\
\hline
\end{tabular}

A favourable outcome in visual acuity (Table 4) was achieved in $59.1 \%(13 / 22)$ of the eyes in the cryotherapy group and $90 \%(27 / 30)$ in the laser group. A visual acuity of $6 / 12$ or better was achieved in $45.5 \%(10 / 22)$ in our cryotherapy group and in 56.7\% $(17 / 30)$ in the laser treatment group. Overall, nine eyes were blind as a result of ROP.

Of the 21 patients in Group 1, seven eyes (16.7\%) were myopic by more than $3.0 \mathrm{D}$. Of these, five eyes were from the cryotherapy group and two eyes were from the laser group. In the cryotherapy group, $5 / 20$ eyes $(25 \%)$ had myopia between 4.5 and 17.5 D. In the laser group, the refractive error was $-7.5 \mathrm{D}$ in both the eyes. Strabismus was observed in eight children (36.4\%): esotropia in six $(27.3 \%)$ patients and exotropia in two patients.

\section{Discussion}

Following the publication ${ }^{4-9}$ of the CRYO-ROP results, cryotherapy became the standard treatment for threshold ROP. Subsequently, however, several reports ${ }^{10-15}$ of binocular indirect ophthalmoscopic (BIO) diode laser photocoagulation treatment for threshold ROP have been published, and laser ablation of the peripheral retina has become increasingly popular. It requires less manipulation of the eye, is associated with less inflammation, fewer systemic and ocular side effects and is technically easier to apply if the disease is posterior.

Some retrospective studies ${ }^{15}$ and several prospective trials ${ }^{10-14,16-18}$ have suggested that laser treatment is at least as effective as cryotherapy in the management of threshold ROP. However, only a few ${ }^{10-12,15-18}$ of them have presented their functional results. We set up a special review clinic to establish data on the structural, visual and refractive outcome in premature infants treated for ROP using cryotherapy and/or laser photocoagulation. A consecutive cohort of treated children was called for assessment according to a strict protocol, between 2 and 13 years after their treatment. We were pleased with the attendance of 21 out of the 29 surviving children (72.4\%), and the access to follow-up data from records on a further six brings to $93.1 \%$ the total of those with available data. (The importance of these additional data is shown by the higher percentage of adverse outcomes in Group 2 children.) While being in part the result of the relative stability of the population in the northeast of England, these figures are also a tribute to the Northern Neonatal Network, which attempts to maintain contact with families of premature infants.

The demographics of our study population are comparable with published data ${ }^{4,10-18}$ including those of the CRYO-ROP study group. The first cryotherapy in our unit was undertaken in 1987, just before the preliminary results of the CRYO-ROP group were published. ${ }^{5}$ Cryotherapy was the treatment of choice until 1994, when the binocular indirect laser ophthalmoscope (BIO) became available to us.

\section{Cryotherapy}

In our cryotherapy study group of 20 eyes with a mean follow-up of 8 years, the structural failure rate was $27.3 \%$ $(6 / 22)$ and the functional failure rate was $40.9 \%(9 / 22)$. A corrected visual acuity of $6 / 12$ or better was achieved in $45.5 \%$. The CRYO-ROP group found, at $5 \frac{1}{2}$-year followup, ${ }^{8}$ an overall unfavourable structural outcome in $26.9 \%$ and a $47.1 \%$ functional failure rate in the treated eyes. In their 10-year follow-up data, ${ }^{9}$ an overall unfavourable structural outcome was observed in $27.2 \%$ and a $44.4 \%$ functional failure rate in the treated eyes. The previously disturbing subgroup trend at $5 \frac{1}{2}$-year follow-up ${ }^{8}$ - that more control eyes than treated eyes had a visual acuity of $6 / 12$ or better - was no longer present in their 10-year follow-up ${ }^{9}$ data.

Our cryotherapy outcome results are, therefore, broadly similar to those of the CRYO-ROP group. In our study, cryotherapy was always administered with either a standard adult retinal cryoprobe or a special ROP probe. This is in contrast to the CRYO-ROP trial where a range of probes, including a cataract pencil, was used. Schulenburg and Acheson ${ }^{21}$ have shown a high risk of inadequate treatment with small-tipped pencils.

\section{Laser}

In comparison with the above results, a corrected visual acuity of $6 / 12$ or better was achieved in a greater 
proportion $(56.7 \%)$ of our laser group of 32 eyes, although those patients were younger at assessment with a follow-up of only 3-7 years. Furthermore, the laser group had a structural and functional failure rate of only $10 \%(3 / 30)$, very consistent with the report from Pearce et al $^{15}$ of a $93 \%$ success in structural outcome and a $91.9 \%$ functional success. Other reports ${ }^{10-15}$ of BIO laser photocoagulation also appear to show a relatively low rate of anatomical failure.

\section{Statistical analysis}

Fisher's exact test shows that the better overall visual outcome in the laser group, as compared with the cryotherapy group, was statistically significant $(P=0.02$, odds ratio $=6.23,95 \%$ confidence interval $=1.44-26.96$ ). However, comparing those who got $6 / 6-6 / 12$ vision, there is no statistically significant difference $(P=0.58$, odds ratio $=1.57,95 \%$ confidence interval $=0.52-4.75$ ). Also, there is no statistically significant difference when comparing those who had a favourable structural outcome $(P=0.14$, odds ratio $=3.38,95 \%$ confidence interval $=0.74-15.40)$. When interpreting these results, it is important to remember that numbers in our study were small.

\section{Strabismus}

Manifest squint was observed in eight patients (36.4\%), six of them being esotropic. Pennefather et $a l^{22,23}$ reported an overall incidence of strabismus of only $12.5 \%$ in babies born at less than 32 weeks gestation, but our children were of rather lower gestational age and, of course, all had ROP.

\section{Myopia}

The association between myopia and prematurity has been recognised for some years. ${ }^{23,24}$ In addition, recent reports ${ }^{16-18}$ have suggested that cryotherapy treatment itself may contribute to the development of myopia (29$91.4 \%$ ) and that laser photocoagulation produces less myopic shift. In our cryotherapy group, $22.7 \%$ of the eyes and in the laser group, $6.3 \%$ of the eyes were more than $3 \mathrm{D}$ myopic. The numbers are too small to subject to statistical analysis.

\section{Conclusion}

We have presented a clinical review of the outcome of treatment of threshold ROP by a single ophthalmologist over 11 years. Our results are consistent with previous studies, which show that treatment with laser photocoagulation seems to be as effective, if not better than, as cryotherapy and can achieve a good structural and functional outcome. We do recognise the limitations in our study: it is not controlled, the number of eyes is small and the change in treatment modality occurred over time. Nevertheless, we believe that studies such as this are of value. The treatment of threshold ROP would certainly seem to justify the investment of resources in ROP screening detailed in the accompanying paper. ${ }^{19}$ It is encouraging to see that the favourable results of the multicentre trial can be achieved in everyday clinical practice, even when including the 'learning curve' of the surgeon involved.

\section{Acknowledgements}

We thank Miss T Smith, Mrs C Hudson (our orthoptists) and Mr K Gales (our optometrist) for their help, and $\mathrm{Mr}$ $\mathrm{K}$ Mitchell for his advice with statistical analysis.

We have no proprietary interest in any of the materials used in this study.

\section{References}

1 Valentine PH, Jackson JC, Kalina RE, Woodrum DE. Increased survival of low birth weight infants: impact on the incidence of retinopathy of prematurity. Paediatrics 1989; 84: 442-445.

2 Gibson DL, Sheps SB, Schechter MT. Retinopathy of prematurity: a new epidemic? Paediatrics 1989; 83: 486-492.

3 Gibson DL, Sheps SB, Uh SH, Schechter MT, McCormick AQ. Retinopathy of prematurity-induces blindness: birthweight-specific survival and the new epidemic. Paediatrics 1990; 86: 405-412.

4 Cryotherapy for Retinopathy of Prematurity Co-operative Group. Multicentre trial of cryotherapy for retinopathy of prematurity. Preliminary results. Arch Ophthalmol 1988; 106: 471-479.

5 Cryotherapy for Retinopathy of Prematurity Co-operative Group. Multicentre trial of cryotherapy for retinopathy of prematurity. Three month outcome. Arch Ophthalmol 1990; 108: 195-204.

6 Cryotherapy for Retinopathy of Prematurity Co-operative Group. Multicentre trial of cryotherapy for retinopathy of prematurity. One-year outcome-structure and function. Arch Ophthalmol 1990; 108: 1408-1416.

7 Cryotherapy for Retinopathy of Prematurity Co-operative Group. Multicentre trial of cryotherapy for retinopathy of prematurity. Three and a half-year outcome - structure and function. Arch Ophthalmol 1993; 111: 339-344.

8 Cryotherapy for Retinopathy of Prematurity Co-operative Group. Multicentre trial of cryotherapy for retinopathy of prematurity. Snellen visual acuity and structural outcome at five and a half years after randomisation. Arch Ophthalmol 1996; 114: 417-424.

9 Cryotherapy for Retinopathy of Prematurity Co-operative Group. Multicenter trial of cryotherapy for retinopathy of prematurity. Ophthalmological outcomes at 10 years. Arch Ophthalmol 2001; 119: 1110-1118. 
10 Goggin M, O'Keefe M. Diode laser for retinopathy of prematurity - early outcome. Br J Ophthalmol 1993; 77: 559-62.

11 Ling CS, Fleck BW, Wright E et al. Diode laser treatment for retinopathy of prematurity: structural and functional outcome. Br J Ophthalmol 1995; 79: 637-641.

12 White JE, Repka MX. Randomised comparison of diode laser photocoagulation versus cryotherapy for threshold retinopathy of prematurity: 3-year outcome. J Paediatr Ophthalmol Strabismus 1997; 34: 83-87.

13 Hunter DO, Repka MX. Diode laser photocoagulation for threshold ROP. Ophthalmology 1993; 100: 238-244.

14 Clark DI, Hero M. Indirect diode laser treatment for stage 3 retinopathy of prematurity. Eye 1994; 8: 423-426.

15 Pearce IA, Pennie FC, Gannon LM, Weindling AM, Clark DI. Three year visual outcome for treated stage 3 retinopathy of prematurity; cryotherapy versus laser. Br J Ophthalmol 1998; 82: 1254-1259.

16 Knight DM, O'Keefe M. Refractive outcome in eyes with retinopathy of prematurity treated with cryotherapy or diode laser: 3 year follow up. Br J Ophthalmol 1996; 80: 998-1001.

17 Laws F, Laws D, Clark D. Cryotherapy and laser treatment for acute retinopathy of prematurity: refractive outcomes, a longitudinal study. Br J Ophthalmol 1997; 81: 12-15.
18 O'Keefe M, O'Reilly, Lannigan B. Longer-term visual outcome of eyes with retinopathy of prematurity treated with cryotherapy or diode laser. Br J Ophthalmol 1998; 82: 1246-1248.

19 Brennan R, Gnanaraj L, Cottrell DG. Retinopathy of prematurity in practice. I: screening for threshold disease. Eye 2003; 17: 181-186.

20 International Committee. An international classification of retinopathy of prematurity. $\mathrm{Br} J$ Ophthalmol 1984; 68: 690-697.

21 Schulenburg WE, Acheson JF. Cryosurgery for acute retinopathy of prematurity: factors associated with treatment success and failure. Eye 1992; 6: 215-220.

22 Pennefather PM, Clarke MP, Strong NP, Cottrell DG, Fritz S, Tin W. Ocular outcome in children born before 32 weeks gestation. Eye 1995; 9(Suppl): 26-30.

23 Pennefather PM, Tin W, Strong NP, Clarke MP, Dutton J, Cottrell DG. Refractive errors in children born before 32 weeks gestation. Eye 1997; 11(Part 5): 736-743.

24 Fledelius HC. Pre-term delivery and subsequent ocular development. A 7-10 year follow up of children scre-ened 1982-84 for ROP. 3) Refraction. Myopia of prematurity. Acta Ophthalmol Scand 1996; 74: 297-300. 